Orthopäde 2016 · 45:607-615

DOI 10.1007/s00132-016-3235-z

Published online: 3 March 2016

(c) The Author(s) 2016. This article is available at SpringerLink with Open Access.

CrossMark

\author{
T. Zhu • Y. Tian · F. Zhou · L. Shang · Y. Guo · Y. Lv \\ Orthopedic Trauma, Peking University Third Hospital, Beijing, China
}

\section{Percutaneous kyphoplasty with or without temporary unipedicle screw reduction}

\author{
A retrospective comparative study of \\ osteoporotic vertebral fractures
}

\section{Introduction}

Percutaneous kyphoplasty (PKP) is a minimally invasive surgical treatment and has become increasingly popular for the treatment of painful osteoporotic vertebral compression fractures (OVCFs) refractory to conservative therapy. Despite excellent clinical results on pain relief and function improvement after PKP, there are still some disadvantages such as unsatisfactory reduction of fracture, bone cement leakage, and postoperative complications including the adjacent and nonadjacent vertebra fractures or the injured vertebra refractures, which always lead to severe pain and dysfunction [1-3].

To achieve better reduction and to minimize complications, we invented a new minimally invasive method-temporary unilateral pedicle screw reduction with percutaneous kyphoplasty (TUSR-

Author Contributions Statement: T. Zhu, as the first author who completed $80 \%$ of the study, was highly involvedin the subject design, clinical data collection as well as the experimental results analysis and discussion. Y. Tian, as one of the corresponding authors, was in charge of all the surgeries mentioned in the article and responsible for guiding the experimental results analysis and discussion. F. Zhou, as one of the corresponding authors, actively participated in the subject design as well as the experimental results analysis and discussion. L. Shang, Y. Guo and Y. Lv, as participants of this study, made their contributions in the patients' postsurgery guidance and follow-up as well as the clinical data collection.
PKP)-where the following were performed prior to traditional PKP: (1) implantation of two Schanz pedicle screws unilaterally in the pedicle of adjacent upper/lower segments percutaneously, (2) connection of the Schanz screws to a longitudinal rod, and (3) use of a distraction tool to achieve satisfactory vertebra reduction. It is speculated that temporary percutaneous pedicle screw reduction with PKP (TUSR-PKP) could be a good choice for the treatment of OVCFs. Hence, a retrospective study comparing the simple PKP (the control group) with TUSR-PKP (the treatment group) was conducted. Our hypothesis was that the TUSR-PKP is noninferior to simple PKP in managing OVCFs.

\section{Patients and methods}

\section{Selection of patients}

In this retrospective study, consecutive patients $(n=140)$ who received treatment for OVCFs in our hospital between January 2012 and January 2014 were initially screened. The study inclusion criteria were as follows: (1) patients older than 50 years; (2) clear trauma history within a week (e. g., fall, road traffic accident); (3) no symptoms or physical findings of nerve damage; (4) a single-level vertebral compression fracture with obvious anterior height loss; (5) severe back pain with preoperative visual analog scale (VAS) score $\geq 7$; and (6) patients who had been followed up for at least 1 year postsurgery. The study exclusion criteria were as follows: (1) patients who could not tolerate surgery; (2) pathologic fracture; (3) multiple-level fractures; (4) patients who failed to follow-up for at least 1 year; and (5) no willingness to participate in this study. As a result, 38 patients were enrolled in the study. The causes of the injury were falls to the ground ( $n=$ 33 ) and traffic accidents $(n=5)$. Prior to surgery, detailed information about both TUSR-PKP and simple PKP approaches, as well as the additional cost and potential benefits associated with TUSRPKP were provided to the selected 38 patients and their families; afterwards, they were asked to make an informed decision. Thus, based on the surgical procedures they preferred, the participants were divided into two groups: the control group (simple PKP, $n=24$ ) and the treatment group (TUSR-PKP, $n=14$ ). The demographic characteristics of the patients are presented in - Tab. 1 . There was no significant difference between the two groups with respect to most demographic parameters; hence, the study protocol was approved by the Ethics Committees of our hospital, and then we requested written informed consent from all participants.

\section{Surgical procedures}

- Before surgery, patients in the treatment group were placed in the prone position under general anesthesia with endotracheal intubation and the position of the pedicle of the injured 


\section{Originalien}

Tab. 1 Demographic characteristics of the two groups

\begin{tabular}{|c|c|c|c|}
\hline & Treatment group & Control group & $P$ value \\
\hline Patients (n) & 14 & 24 & \\
\hline Age (years) ${ }^{\mathrm{a}}$ & $63.93 \pm 6.94$ & $67.63 \pm 9.54$ & $>0.05$ \\
\hline Male:female ratio & $3: 11$ & $5: 19$ & $>0.05$ \\
\hline \multicolumn{4}{|l|}{ Level of fracture } \\
\hline T5 & & 1 & \\
\hline T7 & & 1 & \\
\hline T8 & & 1 & \\
\hline T11 & 1 & 1 & \\
\hline T12 & 4 & 4 & \\
\hline L1 & 7 & 7 & \\
\hline L2 & 0 & 4 & \\
\hline L3 & 1 & 3 & \\
\hline L4 & 1 & 2 & \\
\hline Duration of follow-up (months) & $13.64 \pm 1.28$ & $14.54 \pm 2.43$ & $>0.05$ \\
\hline
\end{tabular}

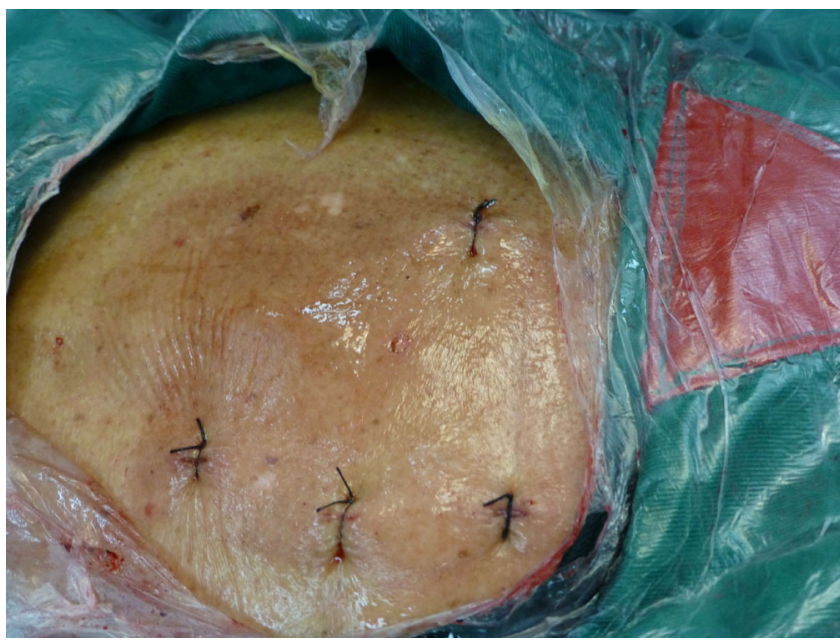

Fig. $1<$ Skin incision design for percutaneous pedicle screw implantation and percutaneous kyphoplasty

vertebra and the unilateral adjacent upper/lower segments were marked on the skin using G-arm fluoroscopy.

- After disinfection and placement of sterile drapes, a skin incision of about $3 \mathrm{~mm}$ was made unilaterally (right or left, depending on which side was seriously injured) in the pedicle of adjacent upper/lower segments. Two Schanz pedicle screws (Synthes, Switzerland) were then implanted percutaneously under G-arm fluoroscopy (• Fig. 1) and a longitudinal rod was then connected with the Schanz screws outside of the skin.

- Next, the distraction reposition of the fractured vertebra was performed along the longitudinal direction of
However, the patients in the control group only underwent traditional PKP. In this study, all surgical procedures were performed by the same team of experienced surgeons and the postoperative care was also managed in the same manner for both groups.

\section{Clinical data}

Clinical data consisting of surgery duration, amount of blood loss, and volume of bone cement injected for both groups were recorded. All perioperative medical or surgical complications were reported and all patients were evaluated on day 1 as well as 1, 3, 6, and 12 months after surgery. The VAS score for pain and the Oswestry Disability Index (ODI), a questionnaire on quantify functional disability related to back pain, were assessed. All imaging data (radiography, computed tomography $[\mathrm{CT}]$, and/or magnetic resonance image [MRI]) were evaluated. The local kyphosis angle (Cobb angle, formed by the inferior end plate of the intact vertebra cephalad to the fracture and the superior end plate of the intact vertebra caudad to the fracture) and the central and anterior vertebral body heights (the measured central and anterior heights divided by that of the intact posterior wall) were measured on lateral plain radiographs of the standing position by two physicians who were not involved in patient care after surgery. A CT scan was used to evaluate bone cement leakage, vertebral refracture, and adjacent and nonadjacent vertebral fractures at least once during the follow-up. All the procedural complications were recorded and all the data were recorded by other physicians who were not involved during surgery to avoid the potential biases (- Figs. 4 and 5).

\section{Statistical analysis}

All the data are recorded as mean \pm standard deviation. Data analysis was performed using SPSS 22.0; $\mathrm{P}<0.05$ was considered statistically significant.

\section{Results}

The results showed that the difference was insignificant between the controlled and 
Orthopäde 2016·45:607-615 DOI 10.1007/s00132-016-3235-z

(c) The Author(s) 2016. This article is available at SpringerLink with Open Access.

\section{T. Zhu $\cdot$ Y. Tian · F. Zhou $\cdot$ L. Shang $\cdot$ Y. Guo $\cdot$ Y. Lv}

\section{Percutaneous kyphoplasty with or without temporary unipedicle screw reduction. A retrospective comparative study of osteoporotic vertebral fractures}

\section{Abstract}

Background. Temporary unipedicle screw reduction with percutaneous kyphoplasty (TUSR-PKP) is a relatively new method for managing osteoporotic vertebral compression fractures (OVCFs). A clinical retrospective comparative study was conducted to verify whether TUSR-PKP was noninferior to simple PKP regarding the management of OVCFs. Methods. A total of 38 consecutive patients who sustained OVCFs without neurological deficits and had undergone surgeries in our hospital from June 2012 to January 2014 were included in the study: 24 patients underwent simple PKP (control group) and the other 14 patients underwent TUSR-PKP (treatment group). All 38 patients were asked to participate in a long-term ( $>1$ year) followup. Visual analog scale (VAS) pain scores and Oswestry Disability Index (ODI) were recorded, and the Cobb angles and the vertebral body heights were measured on the lateral radiographs before surgery and on day 1 , as well as 1, 3, 6, and 12 months after surgery. Results. The patients in the treatment group had better vertebral height gain and greater improvement on ODI compared with the control group $(p<0.05)$. The VAS scores of the two groups were similar at all points until the end of the 1-year follow-up period. Two patients from the treatment group and 5 patients from the control group had cement leakage. In the control group, 3 patients suffered adjacent or nonadjacent vertebra fractures.

Conclusion. TUSR-PKP is a safe and effective surgical option for OVCFs. Compared with simple PKP, TUSR-PKP provided at least equal results for OVCFs. Moreover, during the postsurgery observations, TUSR-PKP showed potential advantages including vertebral height gain, ODI improvement, and fewer subsequent refractures.

\section{Keywords}

Osteoporotic vertebral compression fractures . Reduction - Fractures, bone - Pedicle screws . Spine

\section{Perkutane Kyphoplastie mit oder ohne temporäre Reposition mithilfe unilateraler Pedikelschrauben. Eine retrospektive Vergleichsstudie an osteoporotischen Wirbelfrakturen}

\section{Zusammenfassung}

Hintergrund. Die temporäre Reposition mithilfe unilateraler Pedikelschrauben in Kombination mit der perkutanen Kyphoplastie (TUSR-PKP) ist ein relativ neues Verfahren zur Behandlung osteoporotischer Wirbelkörperkompressionsfrakturen (OVCF). In einer retrospektiven klinischen Vergleichsstudie wurde untersucht, ob die TUSR-PKP der alleinigen PKP in der Behandlung von OVCF nicht unterlegen ist.

Methoden. In die Studie wurden insgesamt 38 konsekutive Patienten mit OVCF eingeschlossen, die keine neurologischen Einschränkungen aufwiesen und in unserer Klinik zwischen Juni 2012 und Januar 2014 einem chirurgischen Eingriff unterzogen wurden. Bei 24 Patienten wurde lediglich eine PKP durchgeführt (Kontrollgruppe), 14 Patienten erhielten eine TUSR-PKP (Behandlungsgruppe). Alle 38 Patienten wurden gebeten, an einer Langzeitnachverfolgung (> 1 Jahr) teilzunehmen. Schmerzintensitäten auf einer visuellen Analogskala (VAS) und der Oswestry Disability Index (ODI) wurden dokumentiert. Cobb-Winkel und die Wirbelkörperhöhe wurden auf lateralen Röntgenaufnahmen vor dem Eingriff sowie 1 Tag, 1, 3, 6 und 12 Monate danach bestimmt. Ergebnisse. Bei den Patienten der Behandlungsgruppe war im Vergleich zur Kontrollgruppe eine größere Zunahme der Wirbelkörperhöhe und eine stärkere Verbesserung des ODI zu verzeichnen $(p<0,05)$. Die VAS-Werte waren in den beiden Gruppen zu allen Zeitpunkten bis zum Ende der 1-jährigen Nachverfolgungsphase vergleichbar. Bei 2 Patienten der Behandlungs- und bei 5 Patienten der Kontrollgruppe kam es zu einem Zementaustritt. In der Kontrollgruppe ereigneten sich bei 3 Patienten Frakturen an angrenzenden oder nichtangrenzenden Wirbelkörpern.

Schlussfolgerung. Die TUSR-PKP ist eine sichere und wirksame chirurgische Option in der Behandlung von OVCF. Im Vergleich zur alleinigen PKP werden mit der TUSR-PKP bei OVCF mindestens gleichwertige Ergebnisse erzielt. Darüber hinaus zeigten sich in der postoperativen Nachverfolgung potenzielle Vorteile des neuen Verfahrens, zu denen die Zunahme der Wirbelkörperhöhe, die ODI-Verbesserung und eine geringere Zahl späterer Refrakturen zählen.

\section{Schlüsselwörter}

Osteoporotische Wirbelkörperkompressionsfrakturen · Reposition · Knochenfrakturen · Pedikelschrauben - Wirbelsäule treatment groups on VAS, ODI $(p>0.05)$ before surgery, but the values of anterior vertebral body height, central vertebral body height, and local Cobb angle differed significantly. It was assumed that the condition of the back pain and physical function were similar between the two groups but vertebral compression was worse in the treatment group.

\section{VAS, ODI scores, and vertebral body height}

In the treatment group, the VAS score was lower immediately after surgery $(2.00 \pm$ 1.58; $p<0.005)$ and at the end of the follow-up period $(0.64 \pm 0.74 ; p<0.005)$ compared to before surgery $(7.89 \pm 1.57)$. The ODI score also was lower immediately after surgery $(0.34 \pm 0.16 ; p<0.005)$ and at the end of the follow-up period $(0.10 \pm 0.04 ; p<0.005)$ compared to before surgery $(0.73 \pm 0.18)$. On the other hand, the anterior vertebral body height increased from $0.56 \pm 0.10$ before surgery to $0.73 \pm 0.11(p<0.005)$ immediately after surgery and to $0.68 \pm 0.11(p<0.005)$ at the end of the follow-up period. The central vertebral body height also increased from $0.60 \pm 0.07$ before surgery to $0.78 \pm$ 
Hier steht eine Anzeige.

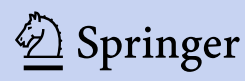




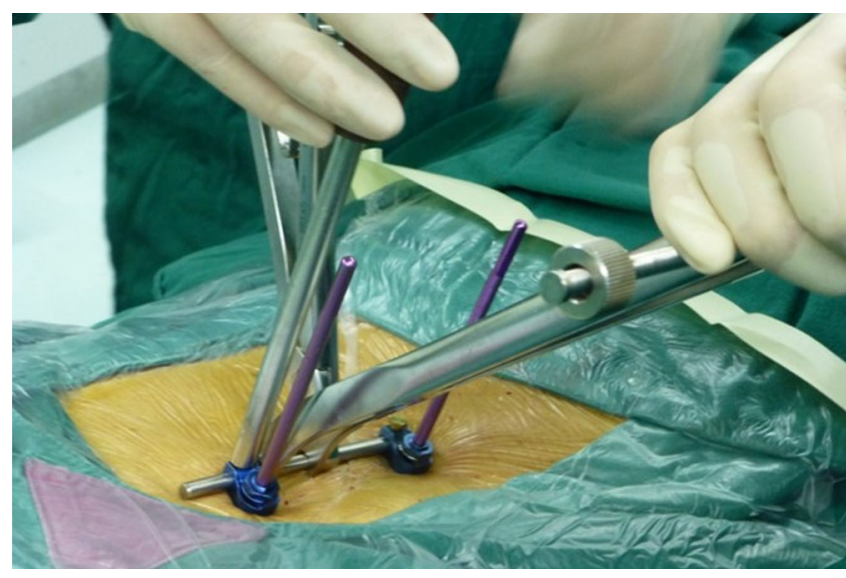

Fig. $2 \Delta$ Temporary unilateral pedicle screw reduction with connecting rod

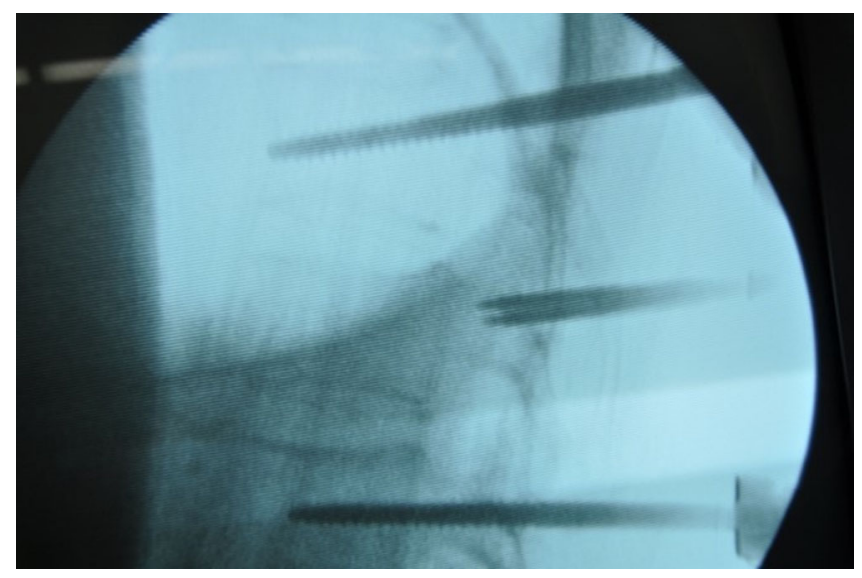

Fig. $3 \Delta$ Intraoperative X-ray showed adequate reduction through Schanz screws $0.11(p<0.005)$ immediately after surgery and to $0.67 \pm 0.13(p<0.005)$ at the end of the follow-up period. The local Cobb angle decreased from $17.97 \pm 4.38^{\circ}$ before surgery to $10.25 \pm 4.51^{\circ}(p<0.005)$ immediately after surgery and was $13.72 \pm$ $4.42^{\circ}(p<0.005)$ at the end of the followup period. By adopting the method of the Bonferroni adjustment, $p<0.01$ is considered statistically significant. Therefore, we observed significant differences $(p<0.005)$ between both pre- and postoperative data and between preoperative and at the 1-year follow-up values of all parameters. All results for the treatment group are presented in $\bullet$ Tab. $\mathbf{2}$.

In the control group, the VAS score was significantly lower immediately after surgery $(2.83 \pm 1.69 ; p<0.001)$ and at the end of the follow-up period $(0.96 \pm 1.08$; $p<0.001)$ compared to before surgery $(8.17 \pm 1.27)$. The ODI was significantly lower immediately after surgery $(0.41 \pm$ $0.12 ; p<0.001)$ and at the end of follow-up period $(0.23 \pm 0.09 ; p<0.001)$ compared to before surgery $(0.75 \pm 0.14)$. The anterior vertebral body height was $0.73 \pm 0.10$ before surgery, $0.77 \pm 0.09(p<0.005)$ immediately after surgery, and $0.72 \pm$ $0.10(p>0.05)$ at the end of the followup period. The central vertebral body height was $0.70 \pm 0.11$ before surgery, $0.79 \pm 0.07(p<0.005)$ immediately after surgery, and $0.75 \pm 0.09(p>0.05)$ at the end of the follow-up period. The local Cobb angle was $13.94 \pm 4.97^{\circ}$ before surgery, $10.91 \pm 4.91^{\circ}(p<0.005)$ immediately after surgery, and $13.55 \pm$ $5.73^{\circ}(p>0.05)$ at the end of the fol- low-up period. By adopting the method of the Bonferroni adjustment, $p<0.01$ is considered as statistically significant. Therefore, we observed a significant difference $(p<0.005)$ not only between pre-and postoperative, preoperative, and 1-year follow-up values of VAS and ODI, but also between pre- and postoperative values of anterior vertebral body height, central vertebral body height, and local Cobb angle; however, a minor difference $(p>0.05)$ was observed between preoperative and 1-year follow-up values of anterior vertebral body height, central vertebral body height, and local Cobb angle. All results for the control group are presented in $\bullet$ Tab. 3 .

In addition, the difference between the two groups with regard to preoperative VAS $(p>0.05)$, postoperative VAS $(p>0.05)$, VAS at the end of the 1-year follow-up period $(p>0.05)$, preoperative ODI $(p>0.05)$, and postoperative ODI $(p>0.05)$ were not significant; however, the ODI of two groups at the end of the follow-up period differed significantly $(p<0.05)$. As a result, the study showed that the treatment group had experienced better long-term functional recovery. Furthermore, in both groups, the vertebral body heights and local Cobb angles immediately after surgery were significantly different compared to preoperative vertebral body heights and local Cobb angles. However, the improvement observed in the treatment group was much better than that in the control group, and the deformity correction was sustained until the end of 1-year follow- up period in the treatment group. While in the control group, the vertebral deformity had returned to the preoperative stage at the end of the 1-year follow-up period. The results show that the patients in treatment group experienced better and long-lasting bone deformity reduction.

\section{Perioperative period parameters}

The surgical duration was $78.07 \pm$ $13.38 \mathrm{~min}$ and $66.29 \pm 16.78 \mathrm{~min}$ in the treatment and control groups, respectively, which was significantly different $(p<0.05)$. The perioperative blood loss $(9.07 \pm 5.38 \mathrm{ml}$ and $7.25 \pm 3.93 \mathrm{ml}$ in the treatment and control groups, respectively) was significantly different $(p>0.05)$. The cement injection (5.25 \pm $1.01 \mathrm{ml}$ and $4.00 \pm 1.07 \mathrm{ml}$ in the treatment and control groups respectively) was significantly different $(p<0.05)$. All the parameters were within the range of the operative tolerance of elderly patients (- Tab. 4).

\section{Postoperative complications}

A total of 2 patients from the treatment group and 5 patients from the control group experienced cement leakage; however, no related symptoms were recorded. Three patients from the control group had suffered with adjacent and nonadjacent vertebra fractures after surgery: two with adjacent vertebrae fracture and one with both adjacent and nonadjacent vertebra fractures. None of the patients had nerve damage after surgery. There was 1 pa- 

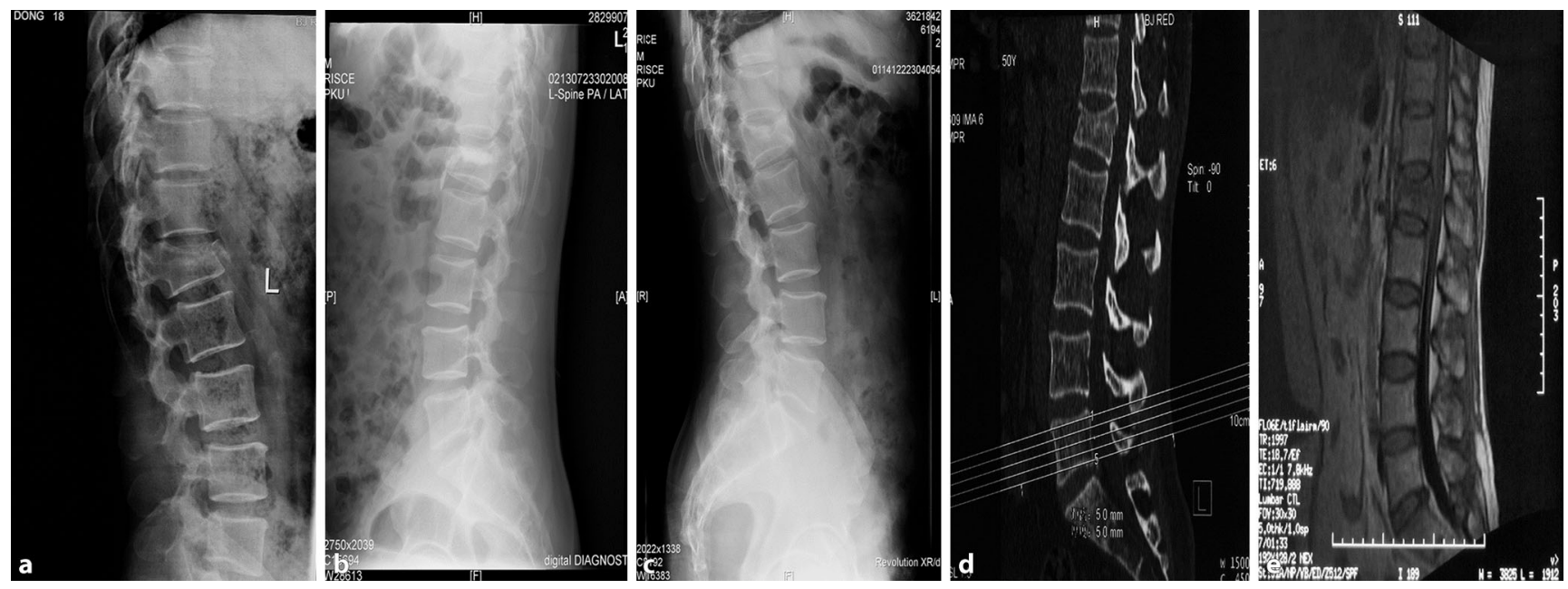

Fig. $4 \Delta$ Radiograph (magnetic resonance imaging $[M R l]$, computed tomography $[C T]$, and X-ray) images of typical case treated with simple percutaneous kyphoplasty: a perioperative $\mathrm{X}$-ray, b postoperative $\mathrm{X}$-ray, c postoperative 17-month follow-up X-ray, d perioperative CT, e perioperative MRI
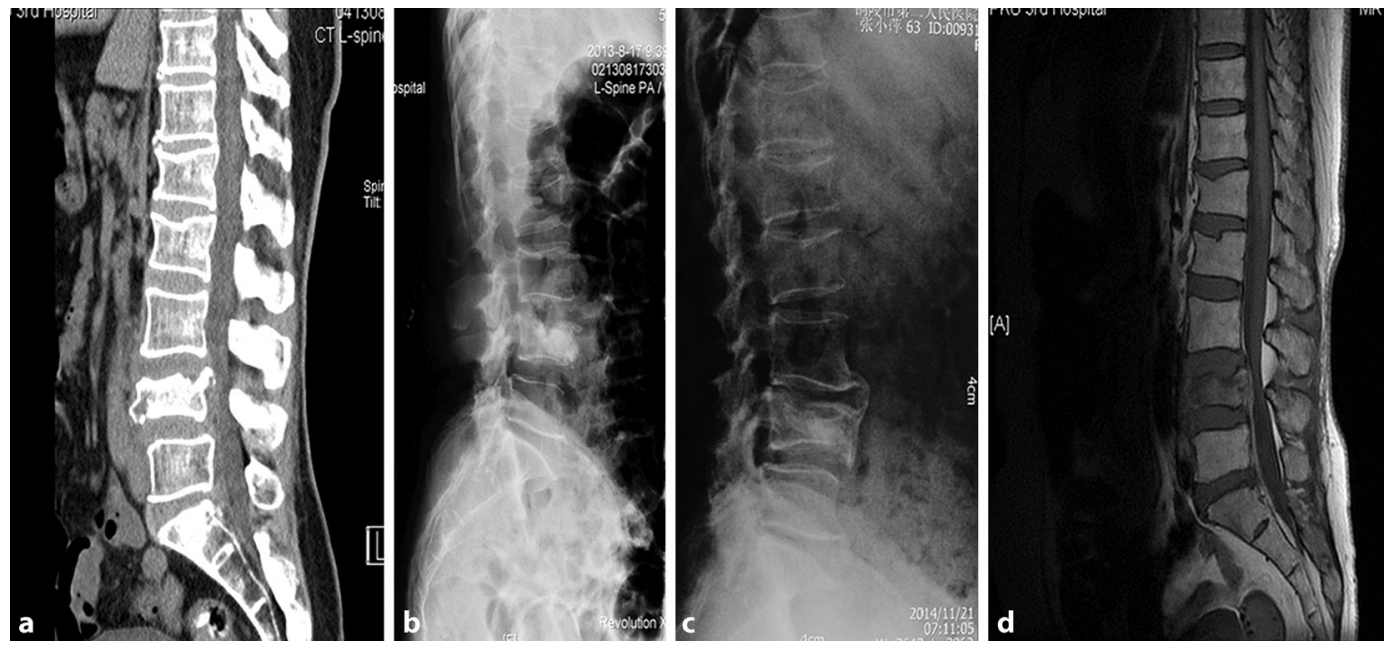

Fig. $5<$ Radiograph (magnetic resonance imaging $[M R I]$, computed tomography [CT], and X-ray) images of typical case treated with temporary unilateral pedicle screw reduction with percutaneous kyphoplasty: a perioperative $\mathrm{CT}$, $\mathrm{b}$ postoperative X-ray, c postoperative 15-month follow-up $\mathrm{X}$-ray, d perioperative MRI

tient in the control group had requested a walking aid. There was no occurrence of new fracture in surgically treated or adjacent vertebrae in the treatment group (- Tab. 4).

\section{Discussion}

PKP is a safe and effective, minimally invasive surgery for the treatment of OVCFs. Theoretically, the technique can be used to correct kyphotic deformities through balloon dilation and injection of cement to stabilize the fractured bone, which ultimately leads to rapid pain relief. Excellent pain relief of PKP had been well documented and it was believed that the immediate pain relief was attributed to immobility and inhibi- tion of micromovement of the fractured fragment after treatment $[4,5]$; however, the application of PKP in bone deformity reduction is limited. Another study [6] showed that postural reduction plays an important role in the kyphosis correction rather than the balloon dilation, and it was unrealistic to expect simple PKP to significantly improve the overall spinal deformity [7]. A literature report suggested that deformity, independent of back pain and patient's age, was a significant factor affecting the functional impairment of these patients [8]. The residual kyphosis after simple PKP may lead to some complications. Adjacent vertebral fracture rates after PKP reported in the literature varied from $6.5-25 \%$ [9-13].
In the present study, the observed rate of nearly $12.5 \%$ was well within this published range. Based on 171 adjacent-segment fractures, it had been proved that in order to avoid subsequent fractures in the same or adjacent level, the vertebral body should be filled adequately and sagittal balance should be obtained with kyphotic angle (KA) correction; balloon kyphoplasty alone could not affect the incidence of subsequent vertebral compression fractures [14]. In a prospective nonrandomized comparative study, Movrin [15] illustrated that altered biomechanics due to local kyphosis was a possible predictive factor for adjacent vertebrae fractures. The subsequent fractures influenced not only the adjacent vertebrae but also the nonadjacent vertebrae [16-19]. 
Tab. 2 Clinical parameters from initial evaluation to last follow-up in the treatment group

\begin{tabular}{|lllllll}
\hline Parameters & Preop & Postop & 1 Month & 3 Months & 6 Months & 1 Year \\
\hline VAS $^{\mathrm{a}}$ & $7.89 \pm 1.57$ & $2.00 \pm 1.58$ & $1.10 \pm 0.57$ & $0.60 \pm 0.70$ & $0.60 \pm 0.89$ & $0.64 \pm 0.74$ \\
\hline ODI & $0.73 \pm 0.18$ & $0.34 \pm 0.16$ & $0.22 \pm 0.14$ & $0.17 \pm 0.07$ & $0.16 \pm 0.15$ & $0.10 \pm 0.04$ \\
\hline Anterior VB height & $0.56 \pm 0.10$ & $0.73 \pm 0.11$ & $0.66 \pm 0.06$ & $0.65 \pm 0.11$ & $0.60 \pm 0.06$ & $0.68 \pm 0.11$ \\
\hline Central VB height & $0.60 \pm 0.07$ & $0.78 \pm 0.11$ & $0.73 \pm 0.11$ & $0.72 \pm 0.07$ & $0.68 \pm 0.03$ & $0.67 \pm 0.13$ \\
\hline Local Cobb angle $\left(^{\circ}\right)$ & $17.97 \pm 4.38$ & $10.25 \pm 4.51$ & $13.23 \pm 3.59$ & $14.46 \pm 5.90$ & $15.46 \pm 2.88$ & $13.72 \pm 4.42$ \\
\hline
\end{tabular}

VAS visual analog scale, ODI Oswestry Disability Index, Preop preoperative, Postop postoperative, VB vertebral body

aValues represented as mean \pm standard deviation

Tab. 3 Clinical parameter from initial evaluation to last follow-up in the control group

\begin{tabular}{llllllll}
\hline Parameters & Preop & Postop & 1 Month & 3 Months & 6 Months & 1 Year \\
\hline VAS $^{\mathrm{a}}$ & $8.17 \pm 1.27$ & $2.83 \pm 1.69$ & $1.31 \pm 0.87$ & $0.65 \pm 0.86$ & $1.00 \pm 0.93$ & $0.96 \pm 1.08$ \\
\hline ODI & $0.75 \pm 0.14$ & $0.41 \pm 0.12$ & $0.28 \pm 0.09$ & $0.23 \pm 0.08$ & $0.21 \pm 0.08$ & $0.23 \pm 0.09$ \\
\hline Anterior VB height & $0.73 \pm 0.10$ & $0.77 \pm 0.09$ & $0.75 \pm 0.97$ & $0.74 \pm 0.10$ & $0.66 \pm 0.13$ & $0.72 \pm 0.10$ \\
\hline Central VB height & $0.70 \pm 0.11$ & $0.79 \pm 0.07$ & $0.79 \pm 0.08$ & $0.77 \pm 0.08$ & $0.70 \pm 0.06$ & $0.75 \pm 0.09$ \\
\hline Local Cobb angle $\left(^{\circ}\right)$ & $13.94 \pm 4.97$ & $10.91 \pm 4.91$ & $12.47 \pm 5.92$ & $12.40 \pm 5.63$ & $16.91 \pm 7.03$ & $13.55 \pm 5.73$ \\
\hline
\end{tabular}

VAS visual analog scale, ODI Oswestry Disability Index, Preop preoperative, Postop postoperative, VB vertebral body

${ }^{2}$ Values represented as mean \pm standard deviation

Tab. 4 Comparison of surgical parameters between treatment and control groups

\begin{tabular}{|lll}
\hline & Treatment group & Control group \\
\hline Operative time $(\mathrm{min})$ & $78.07 \pm 13.38$ & $66.29 \pm 16.78$ \\
\hline Perioperative blood loss $(\mathrm{ml})^{\mathrm{a}}$ & $9.07 \pm 5.38$ & $7.25 \pm 3.93$ \\
\hline Bone cement injection $(\mathrm{ml})^{\mathrm{a}}$ & $5.25 \pm 1.01$ & $4.00 \pm 1.07$ \\
\hline Patients with bone cement leakage & 2 & 5 \\
\hline Patients with fracture $^{\mathrm{b}}$ & 0 & 3 \\
\hline $\begin{array}{l}\text { aValues represented as mean } \pm \text { standard deviation } \\
\text { bPatients who suffered adjacent and nonadjacent vertebra fractures after surgery }\end{array}$ \\
\hline
\end{tabular}

Due to the deformity, the spinal load force line would move forward, and this eccentric loading may contribute to the increased new fractures in osteoporotic vertebrae adjacent and nonadjacent to an uncorrected VCF deformity.

The subsequent fractures of adjacent and nonadjacent levels often result in worsening of back pain and spinal deformity, which would impact the quality of life of the patients. Moreover, the increasing forward bending moment requires an increased counterbalancing posterior force from musculature and ligaments, otherwise the balance would be lost. This would cause paraspinal muscle fatigue and contribute to chronic back pain with osteoporotic spinal kyphotic deformity. In the present study, 3 patients from the control group suffered from adjacent or nonadjacent vertebra fractures and $1 \mathrm{pa}$ tient was unable to walk without crutches because of the posture problems. Hence, in the treatment of OVCFs, deformity reduction is as important as pain relief. Temporary percutaneous pedicle screw reduction would rapidly ease pain as well as effectively correct the kyphotic deformity.

In the present study, the patients in the treatment group had better reduction of OVCF through temporary unilateral pedicle screw reduction, which restored their normal spinal alignment. While in the control group, reduction was not satisfactorily achieved through simple PKP, and the residual kyphosis induced the shift of compressive load path anteriorly to the spine. The ex vivo biomechanical research demonstrated that in the fractured vertebrae, the compressive load path could shift anteriorly by about $20 \%$ of anteroposterior endplate width [20] and it could produce an eccentric load- ing on the anterior wall. A previous study [21] showed that in anteriorly eccentric compression, peak stresses changed everywhere by less than $11 \%$ and moved to the anterior aspect of the vertebral body. Due to the poor quality of osteoporotic bone, the increasing stress would compress the cancellous bone all the time.

The significant advantage of temporary unilateral pedicle screw reduction with PKP over simple PKP was vertebral height gain even for the patients situation of vertebral compression is worse. In temporary unilateral pedicle screw reduction with $\mathrm{PKP}$, two minimally invasive techniques were involved: first, the temporary percutaneous pedicle screw reduction allowed a more powerful correctional force to achieve better spinal deformity correction, and second the PKP could stabilize the fracture fragment through viscous bone cement to achieve rapid pain relief and durable spinal deformity correction. Temporary unilateral pedicle screw reduction with PKP did not result in further risk and the operative time was about $1.5 \mathrm{~h}$ with blood loss of less than $20 \mathrm{ml}$ and with no increase in operative complications compared to simple PKP. These results indicate that TUSR-PKP is safe and effective.

There were concerns regarding TUSR$\mathrm{PKP}$ as to whether the additional proce- 
dure of temporary pedicle screw implantation would result in potential complications such as decrease in stiffness and cause extra back pain of adjacent vertebrae. In the present study, the treatment group did not experience any extra back pain or new fracture in the surgically treated or adjacent vertebrae as the temporary unipedicle screw implantation is a minimally invasive procedure, and it would not affect the overall stiffness of the vertebrae body or did not cause extra back pain for at least 1 year. The authors of the present study believe restoring spinal alignment is more important than the local minimal invasiveness. Overall, this retrospective study demonstrated that TUSR-PKP is effective and safe for the treatment of older OVCF patients.

However, the present study has some limitations. The number of patients was limited and this study was not a randomized controlled trial. Hence, a randomized double-blinded prospective study that involves a larger number of patients with long-term follow-up is necessary to confirm the results of this study.

\section{Conclusion}

There is no significant difference between the control group (simple PKP) and the treatment group (TUSR-PKP) with regard to pain relief. Compared to simple PKP, TUSR-PKP has several advantages including fewer subsequent fractures after surgery and better vertebral height gain and ODI improvement, especially in patients whose vertebral compression situation is worse. The initial hypothesis was supported by evidence from the study that TUSR-PKP is noninferior to simple PKP, i.e., it produced at least equal results in managing OVCFs. The authors recommend temporary unilateral pedicle screw reduction with PKP, which is a safe and effective treatment for OVCFs.

\section{Corresponding address}

\section{Y. Tian}

Orthopedic Trauma, Peking University Third Hospital

No. 49 North Garden Road, HaiDian District, 100191 Beijing, China

tianyunbj@sina.com

\section{F. Zhou}

Orthopedic Trauma, Peking University Third Hospital

No. 49 North Garden Road, HaiDian District, 100191 Beijing, China

zhouf@bjmu.edu.cn

\section{Compliance with ethical guidelines}

Conflict of interest. T. Zhu, Y. Tian, F. Zhou, L. Shang Y. Guo, and Y. Lv state that there are no conflicts of interest.

All studies on humans described in the present manuscript were carried out with the approval of the responsible ethics committee and in accordance with national law and the Helsinki Declaration of 1975 (in its current, revised form). Informed consent was obtained from all patients included in studies.

Open Access. This article is distributed under the terms of the Creative Commons Attribution 4.0 International License (http://creativecommons.org/ licenses/by/4.0/), which permits unrestricted use, distribution, and reproduction in any medium, provided you give appropriate credit to the original author(s) and the source, provide a link to the Creative Commons license, and indicate if changes were made.

\section{References}

1. Ma XL, Xing D, Ma JX, Xu WG, Wang J, Chen Y (2012) Balloon kyphoplasty versus percutaneous vertebroplasty in treating osteoporotic vertebral compression fracture: grading the evidence through a systematic review and meta-analysis. Eur Spine J 21:1844-1859. doi:10.1007/s00586012-2441-6

2. Yimin Y,Zhiwei R, Wei M, Jha R (2013) Current status of percutaneous vertebroplasty and percutaneous kyphoplasty-a review. Med Sci Monit 19:826-836. doi:10.12659/msm.889479

3. Xiao H, Yang J, Feng X, Chen P, Li Y, Huang C, Liang Y, Chen H (2015) Comparing complications of vertebroplasty and kyphoplasty for treating osteoporotic vertebral compression fractures: a metaanalysis of the randomized and non-randomized controlled studies. Eur J Orthop Surg Traumatol 25(Suppl 1):77-85. doi:10.1007/s00590-0141502-4

4. Belkoff SM, Mathis JM, Jasper LE, Deramond H (2001) The biomechanics of vertebroplasty. The effect of cement volume on mechanical behavior. Spine 26:1537-1541 ((Phila Pa 1976))

5. Belkoff SM, Mathis JM, Jasper LE, Deramond H (2001) An exvivo biomechanical evaluation of a hy- droxyapatite cement for use with vertebroplasty. Spine 26:1542-1546 ((Phila Pa 1976))

6. Chin DK, Kim YS, Cho YE, Shin JJ (2006) Efficacy of postural reduction in osteoporotic vertebral compression fractures followed by percutaneous vertebroplasty. Neurosurgery 58:695-700 (discussion 695-700) doi:10.1227/01.neu.0000204313.36531.79

7. Pradhan BB, Bae HW, Kropf MA, Patel VV, Delamarter RB (2006) Kyphoplasty reduction of osteoporotic vertebral compression fractures: correction of local kyphosis versus overall sagittal alignment. Spine 31:435-441. doi:10.1097/01.brs.0000200036.08679.1e

8. Yuan HA, Brown CW, Phillips FM (2004) Osteoporotic spinal deformity: a biomechanical rationale for the clinical consequences and treatment of vertebral body compression fractures. JSpinal Disord Tech 17:236-242

9. Wardlaw D, Cummings SR, Van Meirhaeghe J, Bastian L, Tillman JB, Ranstam J, Eastell R, Shabe P, Talmadge K, Boonen S (2009) Efficacy and safety of balloon kyphoplasty compared with non-surgical care for vertebral compression fracture (FREE): a randomised controlled trial. Lancet 373:1016-1024. doi:10.1016/s01406736(09)60010-6

10. Frankel BM, Monroe T, Wang C (2007) Percutaneous vertebral augmentation: an elevation in adjacentlevel fracture risk in kyphoplasty as compared with vertebroplasty. Spine 7:575-582. doi:[10] 1016/j.spinee.2006.10.020

11. Pflugmacher R, Schroeder RJ, Klostermann CK (2006) Incidence of adjacent vertebral fractures in patients treated with balloon kyphoplasty: two years' prospective follow-up. Acta Radiol 47:830-840. doi:10.1080/02841850600854928

12. Fribourg D, Tang C, SraP, Delamarter R, BaeH (2004) Incidence of subsequent vertebral fracture after kyphoplasty. Spine 29:2270-2276 (discussion 2277)

13. Movrin I, Vengust R, Komadina R (2010) Adjacent vertebral fractures after percutaneous vertebral augmentation of osteoporotic vertebral compression fracture: a comparison of balloon kyphoplasty and vertebroplasty. Arch Orthop Trauma Surg 130:1157-1166. doi:10.1007/s00402-010-1106-3

14. Civelek E, Cansever T, Yilmaz C, Kabatas S, Gulsen S, Aydemir F, Altiotanors N, Caner H (2014) The retrospective analysis of the effect of balloon kyphoplasty to the adjacent-segment fracture in [171] patients. J Spinal Disord Tech 27:98-104

15. Movrin I (2012) Adjacent level fracture after osteoporotic vertebral compression fracture: a nonrandomized prospective study comparing balloon kyphoplasty with conservative therapy. Wien Klin Wochenschr 124:304-311. doi:10.1007/s00508012-0167-4

16. Li X, Yang H, Tang T, Qian Z, Chen L, Zhang Z (2012) Comparison of kyphoplasty and vertebroplasty for treatment of painful osteoporotic vertebral compression fractures: twelve-month followup in a prospective nonrandomized comparative study. J Spinal Disord Tech 25:142-149. doi:10.1097/BSD.0b013e318213c113

17. Omidi-Kashani F, Samini F, Hasankhani EG, Kachooei AR, Toosi KZ, Golhasani-Keshtan F (2013) Does percutaneous kyphoplasty have better functional outcome than vertebroplasty in single level osteoporotic compression fractures? A comparative prospective study. J Osteoporos, doi:10.1155/2013/690329

18. Bae H, Shen M, Maurer P, Peppelman W, Beutler W, Linovitz R, Westerlund E, Peppers T, Lieberman 
I, Kim C, Girardi F (2010) Clinical experience using Cortoss for treating vertebral compression fractures with vertebroplasty and kyphoplasty: twenty four-month follow-up. Spine 35:E1030-E1036. doi:10.1097/BRS.0b013e3181dcda75

19. Kim KH, Kuh SU, Chin DK, Jin BH, Kim KS, Yoon YS, Cho YE (2012) Kyphoplasty versus vertebroplasty: restoration of vertebral body height and correction of kyphotic deformity with special attention to the shape of the fractured vertebrae. J Spinal Disord Tech 25:338-344. doi:[10] 1097/BSD.0b013e318224a6e6

20. Gaitanis IN, Carandang G, Phillips FM, Magovern B, Ghanayem AJ, Voronov LI, Havey RM, Zindrick MR, Hadjipavlou AG, Patwardhan AG (2005) Restoring geometric and loading alignment of the thoracic spine with a vertebral compression fracture: effects of balloon (bone tamp) inflation and spinal extension. Spine 5:45-54. doi:10.1016/j.spinee.2004.05.248

21. Mizrahi J, Silva MJ, Keaveny TM, Edwards WT, Hayes WC (1993) Finite-element stress analysis of the normal and osteoporotic lumbar vertebral body. Spine 18:2088-2096
M. Jagodzinski, N. F. Friederich, W. Müller Das Knie

Form, Funktion und ligamentäre Wiederherstellungschirurgie

Heidelberg: Springer-Verlag Berlin Heidelberg 2016, 2, (ISBN 978-3-642-45000-6), Hardcover, 149.99 EUR

Jeder, der beginnt sich mit der Kniechirurgie zu beschäftigen wird früher oder später auf das epochemachende Werk von Werner Müller zur Biomechanik und ligamentären Wiederherstellungschirurgie stoßen. Nicht zuletzt die überschlagene Viergelenkkette hat Generationen von Kniechirurgen in ihrem Verständnis dieses komplexen Gelenkes geprägt. So häufig, wie dieses Buch und seine Prinzipien in Kursen und Vorträgen zitiert werden, mag es verwundern, dass erst heute - über 30 Jahre nach Erscheinen der Erstausgabe die zweite Ausgabe in völlig neu überarbeiteter Form erscheint.

An dem groben Konzept des Buches hat sich auch in der neuen Ausgabe nichts geändert. Das Buch bietet zu Beginn eine Einleitung zu Anatomie und Biomechanik des Kniegelenkes mit den gewohnten, von Werner Müller bereits in den 80er Jahren erarbeiteten Beispielen und Modellen. Nach einem kurzen Exkurs zu spezifischen Untersuchungstechniken folgt eine Übersicht der gängigen ligamentären Verletzungen und ihrer zugrundeliegenden Mechanismen. Dieses Kapitel ist nicht zuletzt für Kollegen interessant, die sich häufig mit kniegelenksbezogenen Fragestellungen im Rahmen von Gutachten auseinandersetzen müssen. Der nächste Teil des Buches setzt sich schließlich mit den operativen Rekonstruktionsmöglichkeiten von Monound Multiligamentverletzungen auseinander und gibt einen guten Überblick über gängige OP-Verfahren, immer vor dem Hintergrund der biomechanischen Prinzipien. Bemerkenswert an diesem Kapitel ist insbesondere das Sammelsurium allgemeiner operationstechnischer Hinweise wie etwa die Wahl des richtigen Nahtmaterials. Das letzte Kapitel behandelt die Grundsätze der postoperativen Rehabilitation nach rekonstruktiven Eingriffen mit einem Fokus auf den für den Operateur wichtigen Fragestel- lungen zur Immobilisation, Physiotherapie und Belastung.

Die Autoren der neuen Ausgabe sind einerseits um eine hohe Originaltreue bemüht, sorgen aber durch geradlinige Formulierung andererseits auch für ein völlig neues Erscheinungsbild des Buches. Die verwendeten Schemata und Abbildungen sind aufwändig völlig neu bearbeitet und insbesondere koloriert worden, was das Buch im Vergleich zu seiner ersten Ausgabe auf ein zeitgemäßes Niveau hebt. Neben zahlreichen sehr guten Schemata zur Veranschaulichung biomechanischer Sachverhalte enthält das Buch auch eine Menge sehr guter MRT und Röntgenbefunde aus der klinischen Praxis. Auch die zahlreichen anatomischen Präparatefotos bieten einen guten Brückenschlag zwischen Theorie und operativer Praxis, was das Wiedererkennen und die Identifikation spezifischer Strukturen im operativen Umfeld deutlich erleichtert. Das Stichwortverzeichnis ist sehr kurz, bietet aber durch die entsprechende Verschlagwortung eine erstaunlicherweise gute Orientierung.

Das Layout des Buches ist durchgehend vierfarbig gehalten, die Seiten zweispaltig aufgebaut und der Text völlig neu redigiert. DerFließtext ist durchgehend klar geschrieben und um zahlreiche aktuelle Passagen ergänzt worden.

Zusammenfassend lässt sich sagen, dass dieses Buch in seiner völlig neu überarbeiteten zweiten Auflage dem Original alle Ehre macht. Der inhaltliche Umfang ist mit etwa 200 Seiten unverändert geblieben. Der Preis ist absolut angemessen. Ein zeitloser Klassiker.

P. Rößler, Bonn 